\title{
Characteristic Effects of 4,5-Disubstituted Pyridazin-3-one Derivatives with Various Functional Groups: $A$ b initio Study
}

\author{
Yong-Jin Yoon, ', In-Sun Koo, and Jong Keun Park ${ }^{*}$ \\ ${ }^{\dagger}$ Department of Chemistr: Research Institue of Natural Science, Graduate School for Molecula Materials and Nanochemistr?, \\ Gveongsang National University, Jini 660-701, Korea \\ Department of Chemistry Education and Research Institute of Nataral Science, Gyeongsang National University, \\ Jinin 660-701, Korea. E-mail: mc7iagnitac:kr
}

Recened Moy' 15.2007

\begin{abstract}
The geometrical structures of pyridazin-3-one derivatives (4,5-dihalopyridazin-3-one and 4-halo-5alkoxypyridazin-3-one) with various functional and substituent groups were fully optimized using the ab initio Hartree-Fock (IF) and second order Môller-Plesset perturbation (MP2) methods. $\Lambda$ t the N2-, C4-, and C5positions on the pyridazin-3-one rings, the structural and electronic features pertaining to the variations of the functional and substituent groups were analyzed, respectively. The trends in the variation of the bond lengths, atomic charges, and energetics (relative energy, binding energy) of the derivatives induced by changing the electron donating functional groups $(\mathrm{X} 1-\mathrm{OMe}, \mathrm{OEt})$ to electron withdrawing groups $\left(\mathrm{X} 1-\mathrm{Cl}, \mathrm{NO}_{2}\right)$ were examined. The variations of the bond lengths, atomic charges, and binding energies with the electron withdrawing strength of the substituent groups $(\mathrm{Y}-\mathrm{Me} \rightarrow \mathrm{F}$ ) were also investigated.
\end{abstract}

Key Words : Geometrical structure, Bond length, Atomic charge, Flectron donating/withdrawing group. Binding energy

\section{Introduction}

The synthesis and properties of pyridazine derivatives have been studied with various experimental techniques. ${ }^{1-21}$ Since pyridazine nucleosides were recognized as having biological activity ${ }^{1.2}$ and as being useful as synthetic auxiliary materials. ${ }^{34}$ many studies have focused on their synthesis ${ }^{5-15}$ and applications. ${ }^{16-21}$ Particularly, much effort has been made to develop convenient and efficient routes for their synthesis. Pyridazin-3(2H)-one derivatives are ambident anions under basic conditions, ${ }^{3.4}$ acting as stable anions and good leaving groups. That is, pyridazin- $3(2 \mathrm{H})$-one is a useful intermediate for the synthesis of pyridazine derivatives. The nucleophilic/electrophilic substitution reactions at the N2-position of the pyridazin-3(2H)-one ring depend greatly on the electron donating and/or withdrawing groups at the C4- and C5-positions.

In the synthesis of pyridazine derivatives by Yoon's group. ${ }^{6-16}$ the nucleophilic substitution reactions of the pyridazine derivatives rely on both structural and electronic condition factors. The structural factors are the positions and numbers of the substituent groups. The carbon $(\mathrm{C} 5)$ at the 5 position and the nitrogen (N2) at the 2-position on the pyridazine derivatives are the most reactive sites. The electronic condition factors are the electronic characteristics of the substituted functional groups. The product yields of the substitution reaction depend on the electron donating and /or withdrawing groups. (6-16.20-2.7.7 $^{2}$ Multisubstituted pyridazin$3(2 \mathrm{H})$-one derivatives are also useful materials (as intermediates) for the synthesis of some bi- and tricyclic heterocycles and fused ring derivatives. ${ }^{10-10}$ For $\mathrm{N}$-nitration substitution reactions, ${ }^{10}$ the $\mathrm{N} 2$-atom of 4,5 -dihalopyridazin3 -one reacts well with $N$-nitrating reagents such as $\mathrm{Cu}\left(\mathrm{NO}_{3}\right)_{2}$ under neutral conditions, whereas the reaction does not take place under acidic conditions. 4-chloro-5-alkoxypyridazin3-one does not react well with $N$-nitrating reagents such as $\mathrm{Cu}\left(\mathrm{NO}_{3}\right)_{2}$. Meanwhile, in the $N$-nitration of $N$-methylbenzylamine as a secondary amine with 2-nitropyridazin-3one, the 5-alkoxy derivatives show excellent $N$-nitro transfer potentiality to secondary amines, while the 5-halo derivatives<smiles>[X]C1=CNNC([O])=C1[R]</smiles>

(a)<smiles>[X]c1cn[nH]c(=O)c1[X]</smiles>

(b)<smiles>[X]c1cnn([Y])c(=O)c1[X]</smiles>

$\begin{array}{ll}\mathrm{X} 1, & \mathrm{X} 2 \\ \text { OMe, } & \mathrm{CI} \\ \text { Okt, } & \mathrm{CI} \\ \text { Olh, } & \mathrm{CI} \\ \mathrm{CI}, & \mathrm{CI} \\ \mathrm{Br}, & \mathrm{CI} \\ \mathrm{Br}, & \mathrm{Br} \\ \mathrm{NO}_{2}, & \mathrm{CI}\end{array}$

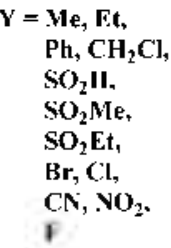

(c)

Scheme 1. The substitution reactions at the N2-position of the pyridarin-3(21)-one derivatives. 
show poor $N$-nitro transfer potentiality. Particularly, the electronic effects of various inorganic materials have been theoretically investigated by Whangbo $s$ group. ${ }^{24,25}$

Although the synthesis and applications of multisubstituted pyridazin- $3(2 \mathrm{H})$-one derivatives have already been studied by several groups, ${ }^{1.21}$ further investigations seem to be worth carrying out. in order to answer the following questions: (i) The N2-atom of multisubstituted pyridazin-3-one derivatives with electron withdrawing groups reacts well with $N$ nitrating reagents such as $\mathrm{Cu}\left(\mathrm{NO}_{3}\right)_{2}$ under neutral conditions, whereas the reaction of these derivatives with electron donating groups does not show good yields under acidic conditions. Is there any relationship between the electron donating and/or withdrawing groups? (ii) Does the $N$-substitution reaction depend on the 4.5-disubstituted pyridazin- $3(2 \mathrm{H})$-one anions as useful internediates for the synthesis? (iii) Does the $N$-substitution reaction depend on the position and the bulky size of the functional and substituent groups? (iv) Does the charge transfer from the functional group at the 4,5-positions to the N2-position take place well? (v) The relative stabilities of the pyridazin$3(2 \mathrm{H})$-one isomers are different from each other. Do the functional and substituent groups of the $\mathrm{C}+\mathrm{C}$. $\mathrm{C} 5-$, and N2positions influence the relative stability? To answer these questions, we optinized the geometrical structures of 4,5 disubstituted pyridazine-3-one derivatives and analyzed the variations of the atomic charges, bond lengths, and binding energies with the electron withdrawing groups.

\section{Computational Methods}

The equilibrium geometrical structures of the pyridazin-3one derivatives (4.5-dihalopyridazin-3-ones and 4-halo-5alkoxypyridazin-3-ones) with various functional (X1. X2 = OMe. Cl: OEt. Cl: OPh, $\mathrm{Cl} ; \mathrm{Cl}$. Cl: Br. $\mathrm{Cl} ; \mathrm{Br}, \mathrm{Br} ; \mathrm{NO}_{2}, \mathrm{Cl}$ ) and substituent ( $\mathrm{Y}=\mathrm{Me}$. Et. Ph, $\mathrm{H}, \mathrm{CH}_{2} \mathrm{Cl}, \mathrm{SO}_{2} \mathrm{H}$. SO-Me. $\mathrm{SO}_{2}$ Et. $\mathrm{Br}$. $\mathrm{Cl}$. CN. NO, F) groups were fully optimized using the $a b$ initio Hartree-Fock (HF) and second order Möller-Plesset perturbation (MP2) methods with large standard basis sets $\left(6-31 \mathrm{G}^{* *}\right.$. $\left.6-311+\mathrm{G}^{* *}\right)$ using the Gaussian $03 .^{36}$ To confinn the existence of stable structures. the harmonic vibrational frequencies of the species were analyzed at the $\mathrm{HF} / 6-311+\mathrm{G}^{* *}$ level. The bond lengths. atomic charges and energetics (relative energy binding energy) of the 4.5-disubstituted py ridazin-3-one derivatives induced by the changes from electron donating to electron withdrawing groups (the functional groups at the C5position and substituent groups at the N2-position) were investigated in detail. In addition the neutrals and anions of the 4.5-disubstituted pyridazin-3-one derivatives were also optimized. The variations of the bond lengths. atomic charges (NBO), and binding energies of the neutrals and anions were also analyzed. in order to investigate the relationship between the electron withdrawing and donating groups. The potential energy barrier and relative energies of the proton transfer reaction from the $(\mathrm{N}-\mathrm{H})$ bond at the N2position to the oxygen atom $(\mathrm{O} 7-\mathrm{H})$ of the ketone group were calculated at the MP2/6-31l+G** level. The relative energy between the isomers and the deprotonation energies of the pyridazin-3-one derivatives were calculated at the $\mathrm{MP} 2 / 6-311+\mathrm{G}^{* *}$ level.

\section{Results and Discussion}

The equilibrium geometrical structures of the 4.5disubstituted pyridazin-3-one derivatives with the various functional $(\mathrm{Xl}, \mathrm{X} 2=\mathrm{OMe} . \mathrm{Cl} ; \mathrm{OEt}, \mathrm{Cl}$ : OPl, $\mathrm{Cl}$ : Cl. Cl; Br. $\mathrm{Cl} ; \mathrm{Br}, \mathrm{Br}$. $\left.\mathrm{NO}_{2}, \mathrm{Cl}\right)$ and substituent $(\mathrm{Y}=\mathrm{Me}$. Et. Pl. $\mathrm{H}$, $\mathrm{CH}_{2} \mathrm{Cl}$. $\mathrm{SO}_{2} \mathrm{H}$. $\mathrm{SO}_{2} \mathrm{Me}, \mathrm{SO}_{2} \mathrm{Et}$. Br. Cl. CN, $\mathrm{NO}_{2}, \mathrm{~F}$. N2 $2^{-}$, $\mathrm{Nl}-\mathrm{H} . \mathrm{Nl}-\mathrm{NO}_{2} . \mathrm{O} 7-\mathrm{H}$ ) groups were fully optimized at the MP2/6-31l+G** levels and the variations of the bond lengths are represented in Figure 1. To investigate the structural and electronic effects induced by the donating/ withdrawing groups of the functional and substituent groups, the summations of two hanmett substitutent constants $\left[\sigma_{\text {pran-OPh }}(-0.320)+\sigma_{\text {neta- } C]}(0.373)=\mathbf{0 . 0 5 3}: \sigma_{\text {pera-OMe }}\right.$ $(-0.268)+\sigma_{\text {neta- } C l}(0.373)=\mathbf{0 . 1 0 5}: \sigma_{\text {para- }- \text { EEt }}(-0.250)+$ $\sigma_{\text {nleta-Cl] }}(0.373)=\mathbf{0 . 1 2 3} ; \sigma_{\text {prara Cl }}(0.227)+\sigma_{\text {neta-Cl }}(0.373)=$ 0.600: $\sigma_{\text {para -Er }}(0.232)+\sigma_{\text {nleta- }-}(0.373)=\mathbf{0 . 6 0 5} ; \sigma_{\text {eran-Br }}=$ $(0.232)+\sigma_{\text {nleta-Br }}(0.391)=\mathbf{0 . 6 2 3}: \sigma_{\text {pera-1io2 }}=(0.778)+$ $\sigma_{\text {nilta-Cl] }}(0.373)=1.151$ ] of the para- and meta-substitutents are scaled on the $\mathrm{X}$-axis. ${ }^{27}$ Due to the change from the electron donating group of $\mathrm{OMe}$ to the electron withdrawing group of $\mathrm{NO}_{2}$, the variations in the lengths of $\mathrm{R}_{(1-2,}, \mathrm{R}_{(2-3) \text {, }}$ and $R_{(3-4)}$ increase, and the variations of $R_{(-5)}$ and $R_{(5-6)}$ decrease. Due to the change in the substituent groups $(Y)$. the bond length of $(1.26 \sim 1.36 \AA)$ at $R_{(1-2)}$ is shorter than the others. while the bond length of $(1.4 \sim 1.48 \AA)$ at $R_{(3-4)}$ is the longest. The optimized bond lengths of the six-membered ring of the pyridazin-3-one derivatives are similar to the bond length $\left(R_{(-C)}=1.34 \AA\right)$ of the double bond. Although the geometric structures of the pyridazin-3-one derivatives are represented in the form of the alternative double bond in Scheme 1, the six membered ring has aromaticity constituted of $\pi$-bonds such as those of the benzene ring. Therefore, the electronic effect induced by the donating/withdrawing groups of the functional and substituent groups influences the bond lengths of the six-membered ring through these $\pi$-bonds. When the electron donating $(\mathrm{Xl}=\mathrm{OMe}$ and $\mathrm{Y}=\mathrm{Me}$ ) groups are bonded to the $\mathrm{C} 5$ and $\mathrm{N} 2$ atoms. the bond lengths on the derivative rings decrease. On the other hand. when the electron withdrawing $\left(\mathrm{Xl}=\mathrm{NO}_{2}\right.$ and $\mathrm{Y}=$ $\mathrm{NO}_{2}$ ) groups are bonded to $\mathrm{C} 5$ and $\mathrm{N} 2$, the bond lengths increase.

Meanwhile. the (N2-Y) bond dissociations at the N2 position of the 4.5-disubstituted pyridazin-3-one derivatives give the corresponding derivative anions of (b). Therefore. the derivative anions without the substituent groups are optimized as stable structures. At the five bond lengths of

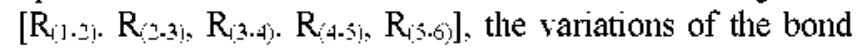
length of the derivative anions without the substituent $(\mathrm{Y})$ groups are more linear than the others. These bond lengths are closer to that of the double bond of $\left(\mathrm{R}_{\mathrm{C} C \mathrm{C}}=1.34 \AA\right)$. The other isomers formed by the bond formations of $(\mathrm{NL}-\mathrm{H}$ and 

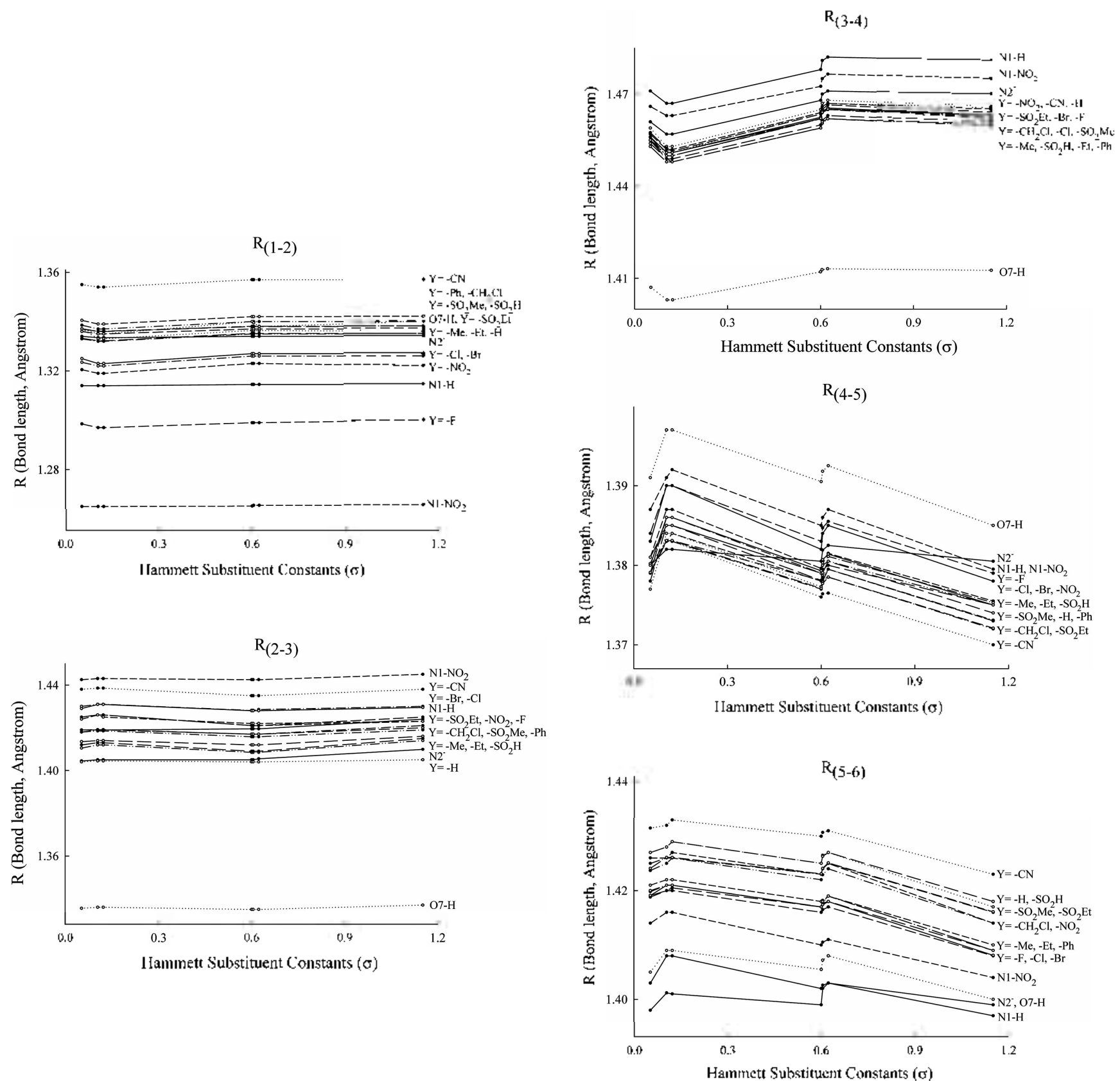

Figure 1. The variations of the bond lengths $(\dot{A})$ of the 4.5-disubstituted pyridazin-3-one derivatives with various functional groups at the

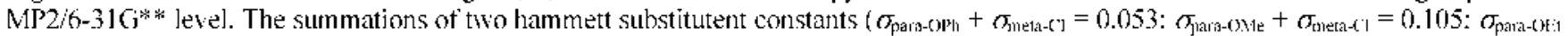

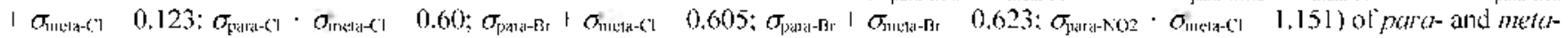
substitutents are sealed on the $X$-ixis. $\times 2$. $\times 1$. and 07 ; the position of the atoms on the six-membered ring.

$\mathrm{Nl}-\mathrm{NO}_{2}$ ) between the $\mathrm{NI}$ atom of the derivative anions and the substituent groups $\left(\mathrm{H}^{+}, \mathrm{NO}_{2}^{-}\right)$are also optimized as stable. The bond lengths of $\left(\mathrm{NI}-\mathrm{H}\right.$ and $\left.\mathrm{NI}-\mathrm{NO}_{2}\right)$ at $\left[\mathrm{K}_{(1-2)}\right.$ and $\mathrm{R}_{[5-(5,1)]}$ are shorter than any of the others, while the bond lengths of $\left(\mathrm{N} 1-\mathrm{H}\right.$ and $\left.\mathrm{N1}-\mathrm{NO}_{2}\right)$ at $\left[\mathrm{K}_{(2-3)}, \mathrm{R}_{(3-4),}\right.$ and $\left.\mathrm{K}_{(4-5)}\right]$ are longer than any of the others.

The atomic charges (NBO) of the 4,5-disubstituted pyridazin-3-one derivatives with the various functional and substituent groups were analyzed at the $M P 2 / 6-311+\mathrm{G}^{* *}$ levels and their variations are represented in Figure 2 . Due to the change from the donating groups (OPh) to the withdrawing groups $\left(\mathrm{NO}_{2}\right)$, the variations of the atomic charge at the $\mathrm{N} 2, \mathrm{C} 3, \mathrm{C} 5$, and $\mathrm{O} 7$ positions (except for the $\mathrm{N} 1$ position) are more positive. As the electron withdrawing character is increased ( $\mathrm{Y}=\mathrm{Me}$, Et. $\mathrm{F}, \mathrm{NO}_{2}$ ), the atomic charges at the $\mathrm{N} 1, \mathrm{~N} 2, \mathrm{C} 5$, and $\mathrm{O} 7$ positions also come to have relatively positive values and the variations of the atomic charge (except for the N1 position) become more positive. Therefore, in the case of the pyridazin-3-one derivatives with the electron donating $X l$ and $Y$ groups, the atomic charges are more negative, while in the case of those with the electron withdrawing groups, the atomic charges 

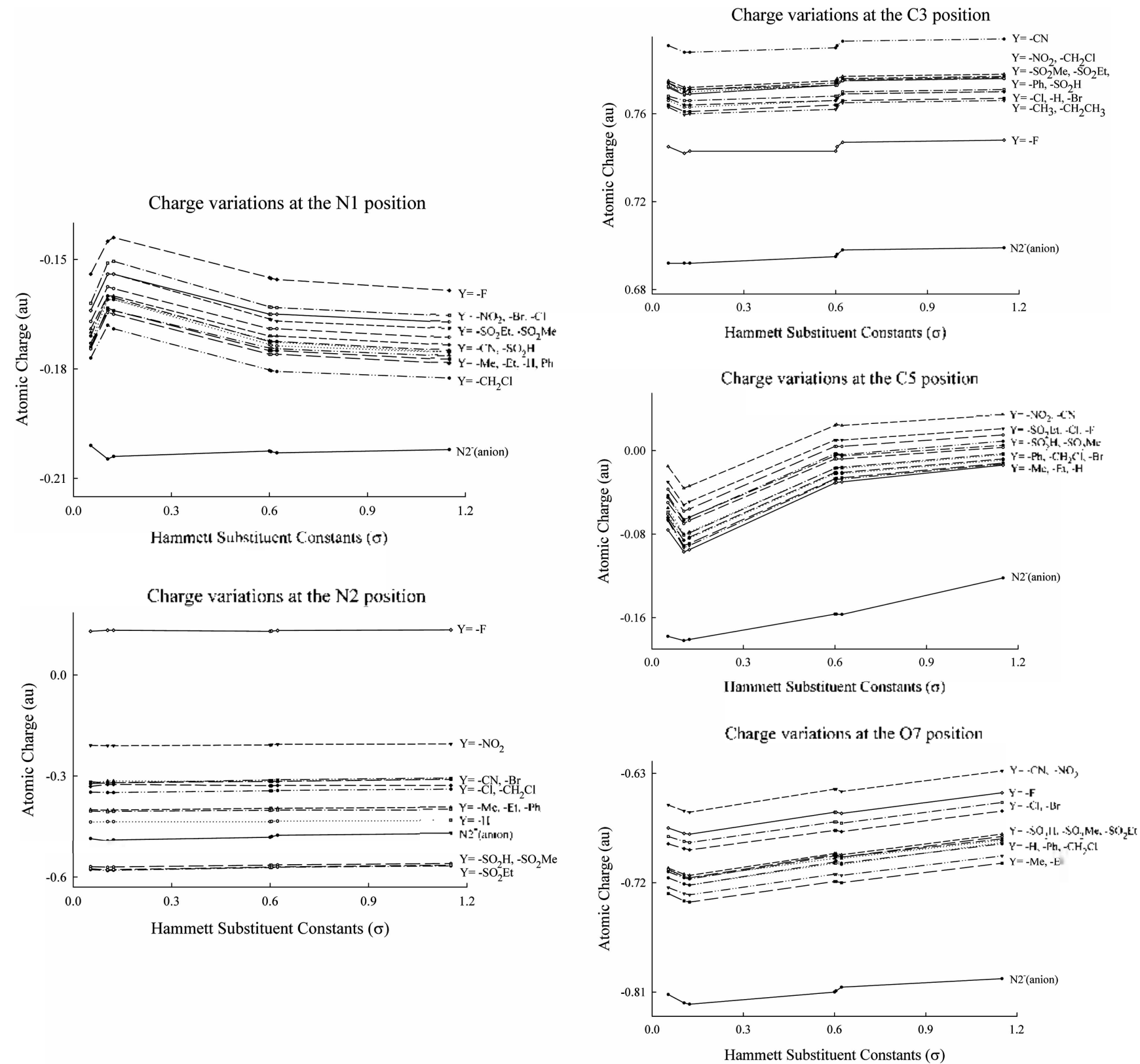

Figure 2. The atomic charges ( $\triangle B \mathrm{BO}$, au) of the 4.5-disubstituted pyridazin-3-one derivatives with various functional groups at the MP2/6-

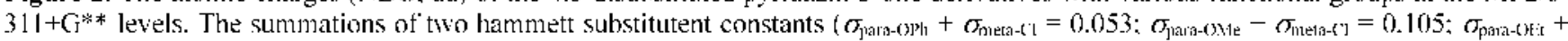

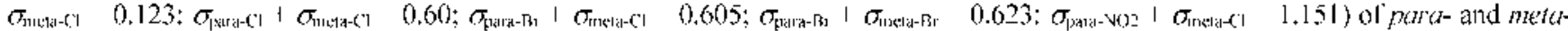
substitutents are scaled on the X-anis.

are more positive. As a result. the electronic effect induced by the donating/withdrawing groups influences the atomic charges of the six-membered rings. Meanwhile, due to the deprotonation [ $(\mathrm{N} 2-\mathrm{H})$ bond dissociation] at their $\mathrm{N} 2$ position, the 4,5-disubstituted pyridazin-3-one derivatives become the corresponding anions. As shown in Figure 2, the atomic charges of the derivative anions have large negative values. As the electron withdrawing strength is increased. the increase of the variations of the atomic charge at the $\mathrm{N} 1$. $\mathrm{N} 2, \mathrm{C} 3, \mathrm{C} 5$, and $\mathrm{O} 7$ positions become more positive than any of the others.

At the $\mathrm{N} 1$ position, the variations of the atomic charge of the 4,5-disubstituted pyridazin-3-one anions $[(\mathbf{b})]$ are more positive, while those of the neutral derivatives [(c)] are more negative. Particularly, at OMe and $O E$ t on the $\mathrm{X}$-axis, the atomic charges of the anionic and neutral derivatives are more negative and positive, respectively. The atomic charge at the $\mathrm{N} I$ position is in the range of $-0,20 \cdots-0.13$ au. At the $\mathrm{N} 2$ position, the atomic charges, except for that of $\mathrm{Y}=\mathrm{F}$. have large negative values. The variation of the atomic charge induced by the electronic effect increases stepwise from $\mathrm{OPh}$ to $\mathrm{NO}_{2}$ with successively increasing step size. The values of the atomic charge are in the range of $0.1 \cdots-0.6 \mathrm{au}$. Due to the negatively large atomic charge $(-0.5 \mathrm{au})$ of the 


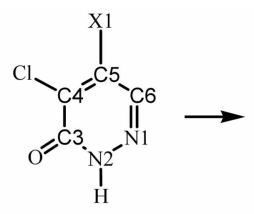

(a)

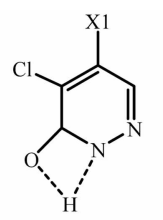

(d)

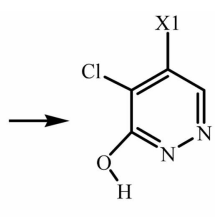

(e)

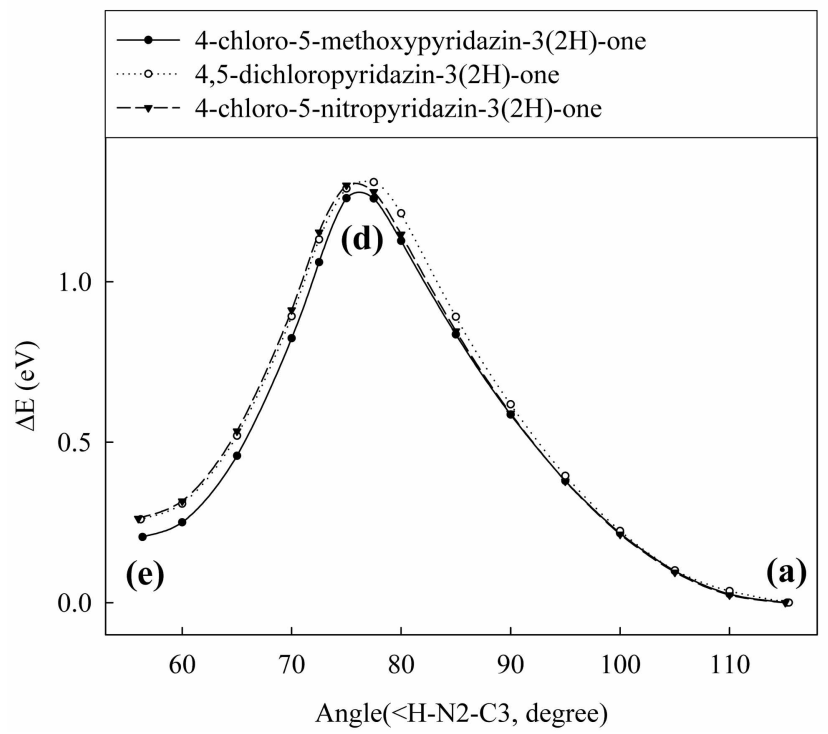

Figure 3. The encrgy tartice $(\mathrm{eV})$ for the proton transfer $(\angle \mathrm{I}-\mathrm{N} 2-$ $\mathrm{C} 3=56-115 \mathrm{dcgres})$ from $(\mathrm{N} 2-\mathrm{H})$ at the 2 -position to $\mathrm{C}=0$ on the 4.5-disubstituted pyridazin-3-one derivatives at the MP2/6-311+ G** level.

derivative anion [(b)], the anionic nitrogen $(\mathrm{N} 2)$ of the derivatives may act as electrophilic agents allowing them to react well with the substituent cations $\left(\mathrm{Y}^{+}=\mathrm{Me}, \mathrm{Et}, \mathrm{Ph}_{n} \mathrm{H}\right.$, $\left.\mathrm{CH}_{2} \mathrm{Cl}, \mathrm{SO}_{2} \mathrm{H}, \mathrm{SO}_{2} \mathrm{Me}, \mathrm{SO}_{2} \mathrm{\Gamma t}, \mathrm{Br}, \mathrm{Cl}, \mathrm{CN}, \mathrm{NO}_{2}, \mathrm{~F}\right)$. Although the functional groups are bonded to the $\mathrm{C} 5$ position. the atomic charges of the $\mathrm{C} 5$ position have relatively small negative values. At the $\mathrm{C} 3$ and $\mathrm{O} 7$ position of the $\mathrm{C}=\mathrm{O}$ group, the atomic charges have large positive and negative values, respectively.

According to the experimental results of Yoon et al. the multisubstituted pyridazin-3-one derivatives are good leaving groups and useful intermediates for the synthesis of the secondary amine derivatives. The $\mathrm{N}$-substitution reaction at the N2-position of the 4.5-disubstituted pyridazin-3-one derivatives gave the corresponding $N$-substituted-products in good yields. Particularly, the functional group at the $\mathrm{C} 4$ and C5 positions depends greatly on the $\mathrm{N}$-substitution reaction at the N2-position. That is, when electron donating groups are bonded to the $\mathrm{C} 4$ and $\mathrm{C} 5$ positions, the $\mathrm{N}$-substitution reaction at the N2-position of the pyridazin-3-one derivatives gave the corresponding products in good yields. On the other hand, when withdrawing groups are bonded to the $\mathrm{C} 4$ and $\mathrm{C} 5$ positions, the $\mathrm{N}$-substitution reaction gave very low yields. These experimental ${ }^{15.23 .29}$ results for the atomic charges are in good agreement with our results.

The relative energy barriers (eV) for the proton transfer from (a) to (e) of the pyridazin-3(2H)-one derivatives with three functional groups $\left(\mathrm{XI}=\mathrm{OMe}, \mathrm{Cl}, \mathrm{NO}_{2}\right.$ ) are repre- sented in Figure 3. The structures of (a) are more stable than those of (e). The relative energy between the two conformers is about $0.20 \cdots 0.26 \mathrm{eV}$. In the case of 4-chloro-5-methoxypyridazin-3(2H)-one with $\mathrm{XI}=\mathrm{OMe}$, the relative energy from (a) to (e) is $0.20 \mathrm{eV}$. Due to the presence of the electron donating group, the atomic charges on the 4-chloro-5methoxypyridazin- $3(2 \mathrm{H})$-one are more negative. The deprotonation by the $(\mathrm{N} 2-\mathrm{H})$ bond dissociation at $(a)$ is relatively difficult. Therefore, the energy gap [(a) and (e)] for the proton transfer is relatively small. On the other hand, in the case of 4-chloro-5-nitropyridazin- $3(2 \mathrm{H})$-one with the electron withdrawing group $\left(\mathrm{XI}=\mathrm{NO}_{2}\right)$, the relative energy between (a) and (e) is $0.26 \mathrm{eV}$. Due to the presence of the electron withdrawing group, the atomic charges on the derivative rings are more positive. By the relatively sinall deprotonation energy at (a), the energy gap between (a) and (e) is relatively large. The transition state of the potential curves appears at $\phi$ $=76.2$ degrees. The transition energy from (a) to the transition state of $(\mathbf{d})$ is about $1.30 \mathrm{eV}$.

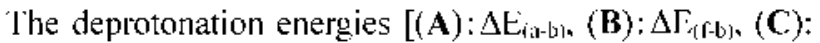
$\left.\Delta \mathrm{E}_{(\mathrm{e}-\mathrm{b})}\right]$, the relative energies between the two isomers [(D):

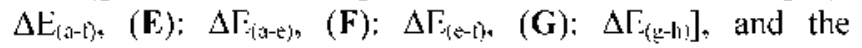
electronic affinities $\left[(\mathbf{H}): \Delta \mathrm{E}_{(\mathrm{b}-\text {-neutal }}\right]$ of the pyridazin-3-one derivatives toward various functional groups are represented in Figure 4. On the $\mathrm{X}$-axis, $[\mathrm{XI}=\mathrm{OMe}$ and $\mathrm{X} 2=\mathrm{Cl}]$, $[\mathrm{XI}=$ $\mathrm{OEt}$ and $\mathrm{X} 2=\mathrm{Cl}],[\mathrm{X} 1=\mathrm{O}]^{\mathrm{Ph}}$ and $\left.\mathrm{X} 2=\mathrm{Cl}\right],[\mathrm{XI}=\mathrm{Cl}$ and $\mathrm{X} 2=\mathrm{Cl}],[\mathrm{X} 1=\mathrm{Br}$ and $\mathrm{X} 2=\mathrm{Cl}],[\mathrm{Xl}=\mathrm{Br}$ and $\mathrm{X} 2=\mathrm{Br}]$. and $\left[X 1=\mathrm{NO}_{2}\right.$ and $\left.X 2=\mathrm{Cl}\right]$ are denoted as $1,2,3,4,5,6$, and 7 , respectively. Due to the changes from 1 to 7 , the deprotonation energies of (A). (B), and (C) decrease. As the withdrawing character increases, the charge density at the $\mathrm{N} 2$ position becomes more positive. That is, the $(\mathrm{N} 2-\mathrm{H})$ bond strength between $\mathrm{N} 2$ and $\mathrm{H}$ become weaker. The deprotonation of the $(\mathrm{N} 2-\mathrm{H})$ bonds at the $\mathrm{N} 2$ position easily occurs and, consequently, the proton $\left(\mathrm{H}^{+}\right)$can move to the nitrogen atom $(\mathrm{NI})$ or the oxygen atom $(\mathrm{O} 7)$. The compounds ( $f$ ) and (e) can be formed. The relative stability of the three isomers is in the order of $(\mathbf{A})>(\mathbf{C})>(\mathbf{B})$. The decreasing trends of the deprotonation energies at the $(\mathbf{A})$, $(\mathbf{B})$, and $(\mathbf{C})$ plots are similar to each other. The energy gap from $\mathrm{Xl}=\mathrm{OCH}_{3}$ to $\mathrm{X} 1=\mathrm{NO}_{2}$ at the MP2/6-311+G** levels is in the range of $0.59-0.67 \mathrm{eV}$. The energy gap between the two basis sets is about $0.5 \mathrm{eV}$.

Except for $\left[(\mathbf{E}): \Delta \mathrm{E}_{(a-e)}\right]$, the relative energies of $[(\mathbf{D})$ :

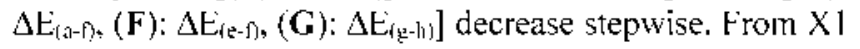
$=\mathrm{OCH}_{3}$ to $\mathrm{XI}=\mathrm{NO}_{2}$, the decrease $(\Delta \mathrm{E}=0.03 \sim 0.08 \mathrm{eV})$ in the relative energies at the MP2/6-311+G** levels is relatively small. As the withdrawing effect ( $\mathrm{Y}=\mathrm{OMe} \rightarrow$ $\mathrm{NO}_{2}$ ) increases, the potential energy of the (e) molecule increase substantially, while the potential energy of (a) and (f) decrease. The increase in the potential energy gap of (e) is larger than those of (a) and (f). As a result, the relative energies of $[(\mathbf{D})$ and $(\mathbf{F})]$ decrease. while that of $(\mathbf{E})$ increases. Meanwhile, as the electron withdrawing effect increases, the potential energies of the anions and neutrals become more unstable. Therefore, the energy gap of $[(\mathbf{H})$ : $\left.\Delta \mathrm{E}_{[\text {[l-neutral }]}\right]$ increases. 
<smiles></smiles>

(a)
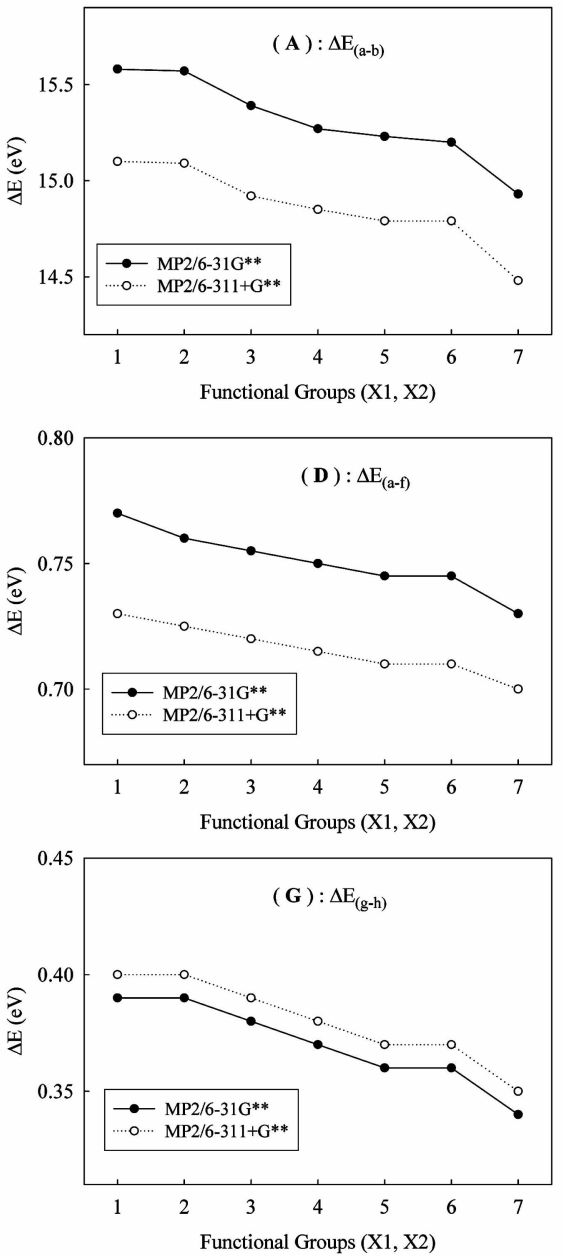

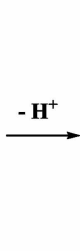

(e)<smiles>[X]c1cnn([N+](=O)[O-])c(=O)c1[X]</smiles>

(b)

(g)<smiles></smiles>

(h)

$\mathbf{X 1}, \quad \mathbf{x} 2$

OMe, $\mathrm{Cl}$

OEt, $\quad$ Cl

OPh, $\quad$ Cl

Cl, $\quad$ Cl

$\mathrm{Br}, \mathrm{Cl}$

$\mathrm{NO}_{2}, \mathrm{Cl}$
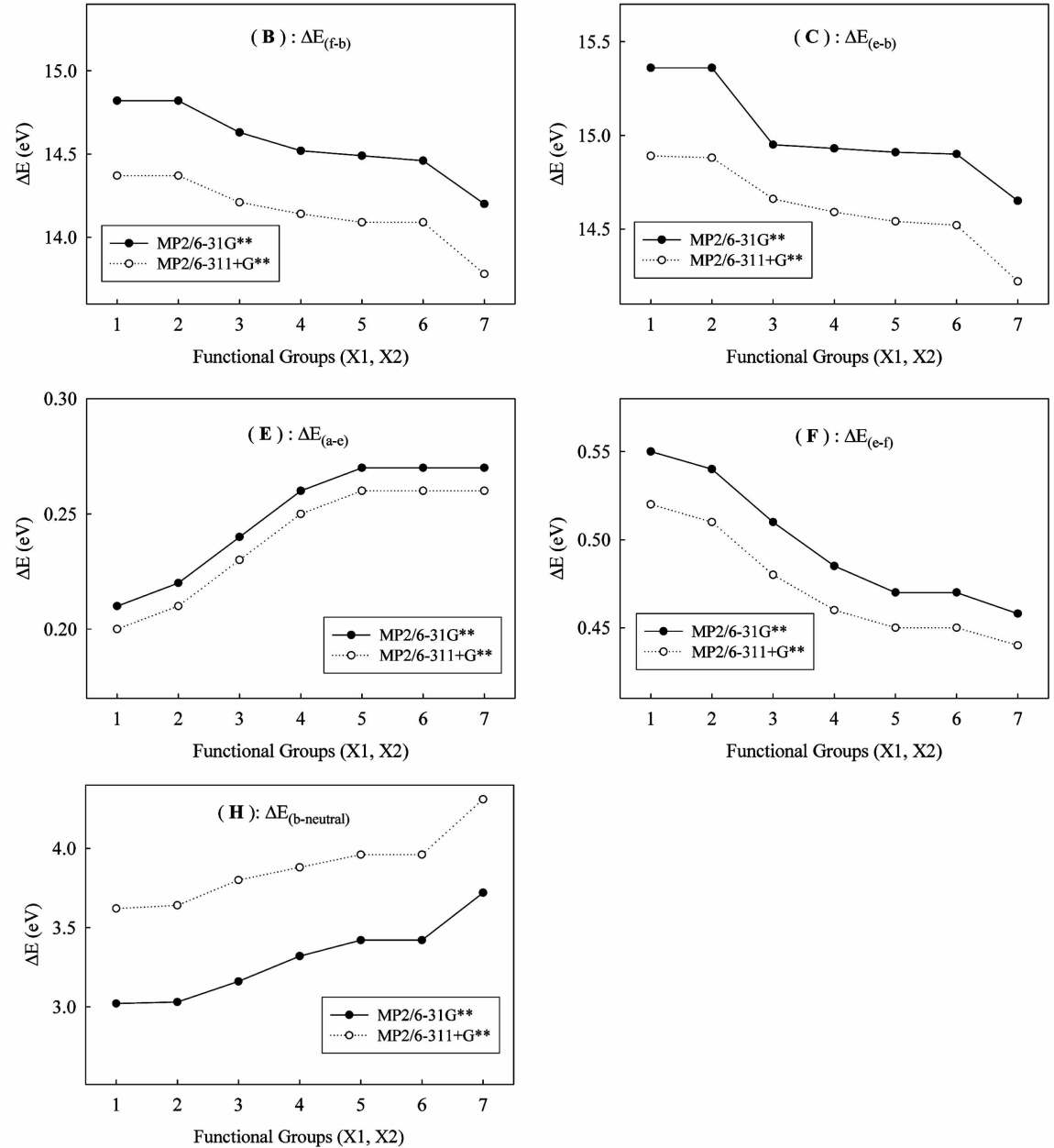

Figure 4. 'The deprotonation energies (eV) and relative energies (eV) of the pyridazin-3-one derivatives with various functional groups

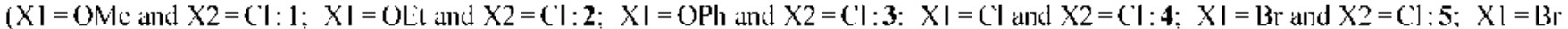
and $\mathrm{X} 2=\mathrm{Br}: 6: \mathrm{XI}=\mathrm{NO})_{2}$ and $\mathrm{X} 2=\mathrm{Cl}: 7$ on the $\mathrm{X}$-axis. $)$ at the $\mathrm{MP} 2 / 6-3 \mathrm{I} 1+\mathrm{C} \mathrm{j}^{* *}\left(6-31 \mathrm{G}^{* *}\right)$ levels.

The binding energy (eV) between the 4,5-disubstituted pyridazin-3-one derivative anions $[(\mathbf{b})]$ and the $\mathrm{Y}$ cations at the $\mathrm{MP}^{2} / 6-311+\mathrm{G}^{* *}\left(6-31 \mathrm{G}^{* *}\right)$ levels are listed in Table 1. The binding energy between the derivative anion and the $\mathrm{Y}$ cation decreases stepwise from $\left(\mathrm{Xl}=\mathrm{OCH}_{3}, \mathrm{X} 2=\mathrm{Cl}\right)$ to $\left(\mathrm{X} 1=\mathrm{NO}_{2}, \mathrm{X}_{2}=\mathrm{Cl}\right)$. Due to the electron donating effect of $\left(\mathrm{X} 1=\mathrm{OCH}_{3}, \mathrm{X} 2=\mathrm{Cl}\right)$, the negative charges on the derivative anions relatively increase. Particularly, the negative charge on the $\mathrm{N}^{2}-$ atom increases. Therefore, the binding interaction between the derivative anion with $\left(\mathrm{XI}=\mathrm{OCH}_{3}\right)$ and the $\mathrm{Y}$ cation is relatively strong and the binding energy is larger than those of the others. On the other hand, due to the electron withdrawing effect of $\left(X 1=\mathrm{NO}_{2}, \mathrm{X} 2=\mathrm{Cl}\right)$, the negative charge on the anions decreases. The binding interaction between the anion with $\left(\mathrm{XI}=\mathrm{NO}_{2}\right)$ and the $\mathrm{Y}$ cation is relatively weak and the binding energy is smaller than the others. Meanwhile, in the case of the donating substituent ( $\mathrm{Y}=\mathrm{Me}$ ) group, the relative gaps of the binding energy between the anions from $\left(\mathrm{XI}=\mathrm{OCH}_{3}\right)$ to $\left(\mathrm{Xl}=\mathrm{NO}_{2}\right)$ and the cation is smaller than those of the others, while in the case of the withdrawing substituent $\left(\mathrm{Y}=\mathrm{NO}_{2}\right)$, the relative gap of the binding energy is larger than those of the others. As a result, in the case of both donating groups $\left(\mathrm{XI}=\mathrm{OCH}_{3}\right.$, $\mathrm{Y}=\mathrm{Me}$ ), the binding energy between the anions and the cation is larger, while in the case of both withdrawing groups $\left(X 1=\mathrm{NO}_{2}, \mathrm{Y}=\mathrm{NO}_{2}\right.$ ), the binding energy is smaller. In the case of the $(\mathrm{Y}=\mathrm{F}$ ) cation, the absolute value of the binding energy is larger than those of the others. The values of the 
Table 1. The binding energies ( $\mathrm{VV}$ ) between the 4.5-disubstituted pyridazin-3-one derivative anions $(\mathrm{X} 1=\mathrm{OMe}, \mathrm{X} 2=\mathrm{Cl}: \mathrm{X} 1=\mathrm{OFt} . \mathrm{X} 2=$

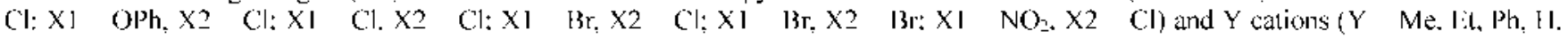

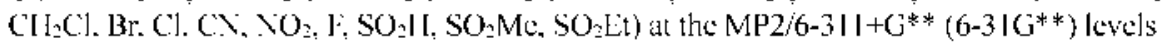<smiles>[X]c1cnn([Y])c(=O)c1[X]</smiles>

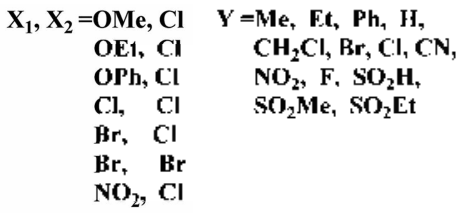

(b)

(c)

\begin{tabular}{|c|c|c|c|c|c|c|c|c|c|c|c|c|c|c|}
\hline$X 1, X 2$ & $\begin{array}{c}\mathrm{MI}_{2} \\
\text { hasis set }\end{array}$ & $\begin{array}{c}\Delta \mathrm{H} \\
\Leftrightarrow \mathrm{SH}=1\end{array}$ & $\begin{array}{c}\Delta \mathrm{E} \\
(Y \mathrm{E}(t)\end{array}$ & $\begin{array}{c}\Delta \mathrm{E} \\
\left(Y^{\prime} \mathrm{P}^{\prime} \mid\right)\end{array}$ & $\begin{array}{c}\Delta E \\
(111)\end{array}$ & $\begin{array}{c}\Delta \mathrm{E} \\
\text { (rellacl) }\end{array}$ & $\begin{array}{c}\Delta \mathrm{E} \\
\Delta \mathrm{Bn}^{\prime \prime}\end{array}$ & $\begin{array}{c}\Delta \mathrm{E} \\
\left(\mathrm{C}_{\mathrm{C}} \mathrm{l}\right.\end{array}$ & $\begin{array}{c}\Delta \mathrm{E} \\
(\mathrm{Y}(\mathrm{N})\end{array}$ & $\begin{array}{c}\Delta \mathrm{E} \\
\left(\mathrm{N}_{\mathrm{N}} \mathrm{O}\right) \mathrm{r}\end{array}$ & $\begin{array}{l}\Delta \mathrm{E} \\
(r+r)\end{array}$ & $\begin{array}{c}\Delta \mathrm{E} \\
\text { (1) sone[ }\end{array}$ & $\begin{array}{c}\Delta \mathrm{E} \\
\text { (s soste) }\end{array}$ & $\begin{array}{c}\Delta \mathrm{E} \\
(\mathrm{r} S O \text { SOEL }\end{array}$ \\
\hline \multirow[t]{2}{*}{-OMe. -Cl } & $6-31 C^{* *}$ & 11.12 & 9.55 & 10.18 & 1.97 & 9.93 & 13.11 & 14.42 & 15.56 & 7.75 & 19.10 & 9.10 & 8.43 & 8.21 \\
\hline & $6-311 \cdot c^{* * *}$ & 10.71 & 9.15 & 9.93 & 1.49 & 9.55 & 12.40 & 13.96 & 15.16 & 7.33 & 20.43 & 8.70 & 8.04 & 7.87 \\
\hline \multirow[t]{2}{*}{-OrL, -C1 } & $6-310^{* * *}$ & 11.12 & 9.55 & 10.18 & 1.97 & 9.93 & 13.11 & 14.41 & 15.56 & 7.75 & 19.10 & 9.10 & 8.43 & 8.21 \\
\hline & $6-311 \cdot \mathrm{C}^{* 8}$ & 10.69 & 9.14 & 9.92 & 1.48 & 9.54 & 12.39 & 13.95 & 15.15 & 7.32 & 20.42 & 8.70 & 8.04 & 7.87 \\
\hline \multirow[t]{2}{*}{-Ol’h, -Cl } & $6-310^{* *}$ & 10.92 & 9.35 & 9.99 & 1.78 & 9.73 & 12.91 & 14.22 & 15.36 & 7.55 & 18.90 & 8.91 & 8.23 & 8.01 \\
\hline & $6-311 \cdot 0^{* 8}$ & 10.50 & 8.94 & 9.73 & 1.29 & 9.35 & 12.19 & 13.76 & 14.95 & 7.12 & 20.22 & 8.50 & 7.84 & 7.67 \\
\hline \multirow[t]{2}{*}{$-C \mathrm{C}, \mathrm{Cl}$} & $6-31 \mathrm{C}^{* *}$ & 10.82 & 9.25 & 9.88 & 1.66 & 9.60 & 12.77 & 14.08 & 15.19 & 7.39 & 18.76 & 8.74 & 8.08 & 7.86 \\
\hline & $6-3111 \cdot \mathrm{C}^{* *}$ & 10.48 & 8.92 & 9.71 & 1.25 & 9.30 & 12.13 & 13.69 & 14.87 & 7.05 & 20.15 & 8.42 & 7.78 & 7.61 \\
\hline \multirow[t]{2}{*}{$-13 r,-C \mid$} & $6-3) C^{* * *}$ & 10.78 & 9.22 & 9.85 & 1.63 & 9.57 & 12.74 & 14.05 & 15.15 & 7.36 & 18.68 & 8.70 & 8.04 & 7.83 \\
\hline & $6-311 \cdot 0^{* *}$ & 10.45 & 8.89 & 9.68 & 1.22 & 9.27 & 12.10 & 13.66 & 14.84. & 7.02 & 20.12 & 8.38 & 7.75 & 7.58 \\
\hline \multirow[t]{2}{*}{$-13 r-13 r$} & $6-311^{* * *}$ & 10.75 & 9.18 & 9.81 & 1.59 & 9.53 & 12.71 & 14.02 & 15.12 & 7.32 & 18.65 & 8.67 & 8.01 & 7.80 \\
\hline & $6-311 \cdot(j * *$ & 10.42 & 8.86 & 9.65 & 1.19 & 9.24 & 12.07 & 13.63 & 14.81 & 6.99 & 20.10 & 8.36 & 7.72 & 7.55 \\
\hline \multirow[t]{2}{*}{$-\mathrm{NO}_{2}-\mathrm{Cl}$} & $6-31 \mathrm{C}^{* * *}$ & 10.49 & 8.92 & 9.55 & 1.32 & 9.25 & 12.42 & 13.73 & 14.79 & 7.01 & 18.61 & 8.36 & 7.72 & 7.50 \\
\hline & $6-311 \cdot 0^{* *}$ & 10.11 & 8.57 & 9.34 & 0.88 & 8.92 & 11.75 & 13.32 & 14.44 & 6.61 & 19.76 & 8.00 & 7.38 & 7.21 \\
\hline
\end{tabular}

binding energy at the MP2/6-311+G** level are smaller than those at the $\mathrm{Ml}^{2} 2 / 6-31 \mathrm{G}^{* *}$ level.

\section{Conclusions}

We optimized the geometrical structures of the 4,5-disubstituted pyridazin-3-one derivatives with seven functional groups at the $\mathrm{C} 5$-position and thirteen substituent groups at the N2 position. The six-membered ring of the 4,5disubstituted pyridazin-3-one derivatives has the aromaticity of the double bond (bond length $=1.26 \cdots 1.46 \AA$ ), viz. the $\pi$ bond. The charge transfer effect through the $\pi$-bond greatly influences the bond lengths and atomic charges of the sixmembered heterocycles. Due to the change from electron donating groups $(\mathrm{Xl}=\mathrm{OMe}$ ) to electron withdrawing groups $\left(X 1=\mathrm{NO}_{2}\right)$, the variations of the bond lengths increase and the variations of the atomic charge at the $\mathrm{N} 2$. $\mathrm{C} 3, \mathrm{C} 5$, and $\mathrm{O} 7$ positions are more positive. The atomic charges of the derivatives with $\left(\mathrm{Y}=\mathrm{F}, \mathrm{NO}_{2}\right)$ are more positive than those with ( $\mathrm{Y}=\mathrm{Me}$. Et). The variational gap of the atomic charge at the $\mathrm{N} 2$ position is larger than those at the other positions. The atomic charges of the anions deprotonated at $\mathrm{N} 2$ have a relatively large negative value. Meanwhile. in the case of proton transfer from (a) to (e), the structure of (a) is more stable and the relative energy of the derivatives with $X_{1}=O M e$ is lower. Due to the change of the functional groups from $\left(\mathrm{Xl}=\mathrm{OCH}_{3}\right)$ to $\left(\mathrm{XI}=\mathrm{NO}_{2}\right)$, the deprotonation energies, relative energies, and binding ener- gies decrease stepwise. The variations of the bond lengths increase, the variations of the atomic charges become more positive, and the variations of the deprotonation energies, relative energies, and binding energies decrease as one goes from electron donating groups $\left(X 1-O C H_{3}, Y-M e\right)$ to electron withdrawing groups $\left(X 1-\mathrm{NO}_{2}, \mathrm{Y}-\mathrm{NO} \mathrm{O}_{2}\right)$

Acknowledgment. This rescarch was supported by a grant (code: F0004021) from the Information Display R\&D Center, one of the $21^{\text {st }}$ Century Frontier R\&D Programs funded by the Ministry of Commerce. Industry and Energy of the Korean Government. The support from Gyeongsang National University Research Fund is also acknowledged.

\section{References}

1. Giviewicy. J.: Wnuk. S. F.: Robins. M. J. J. Org. (hem. 1999. 6t. 2149.

2. Daszkicwicz. Z.: Domanski. A.: Kyziol. J. B. Org. Prep. Proced. Int. 1994. 26. 337 .

3. Martin, II: Patrick, I. T.. J. Heteroclicl. (hem, 1972, 9, 215.

4. Kim. S. K.: Cho. S.-D.: Kweon. I). H.: Yoon. Y. I.: Kim. I. H.: I leo. J. N. J. Heterocyct. ('/rem. 1997. 3\$. 209.

5. Bryant. R. L.: Kuntug. F. A.: South. M. S. J. Heterenel. (hem. 1995. 32. 1473 .

6. Kim. S. K.: Cho. S.-[D.: Kweon. D. H.: Loc. S. Gi: Chung. I. W.: Shin, S. C.: Yoon. Y. J. J. Ileteroclel. ('hem, 1996. 33, 245.

7. Chumg. I1. A.: Kweon. D. H.: Kang. Y. J.: Park. I. W.: Yoon. Y. J. f. Heterocyl (hem 1999. 36.905.

8. Kang. Y. J.: Chung. H. A.: Kinl. J. J.: Yoon. Y. J. Swnthesis 2002. 733. 
9. Chung. H. A.: Kim. J. J.: Cho. S.-D.: Lee. S. G.: Yoon. Y. J. J. Heterocycl. Chent 2002.39.685.

10. Park. Y. D.: Kim. H. K.: Kim. J. J.: Cho. S.-D.: Kim. S. K.: Shiro. M.: Yoon. Y. I. J. Org. Chem. 2003. 68.9113.

11. Park, Y. D.: Kim. J. J.: Chung. H. A.: Kweon, D. H: Cho, S.-D.: Lee, S. G.: Yoon, Y. J. Symthesis $2003,560$.

12. Lee. S. G.: Kim. J. J.: Kim. H. K.: Kweon. D. H.: Kang. Y. J.: Cho. S.-D.: Kim. S. K.: Yoon. Y. J. Current. Org. Chem. 2004. 8. 1463.

13. Kim, J. I.: Park, Y. D.; Cho, S.-D.: Kim. H. K. Chung, H. A.: Lee, S. G. Falck I. R.: Yoon. Y. I. Tetrahedron Lett. 2004. 45.8781

14. Park; Y. D.; Kim. J. J.: Cho. S.D.: Lee. S. G.: Falck. I. R: Yoon. Y. J. Sinthesis 2005.1136.

15. Kim. S. K.: Kweon. D. H.: Cho. S.-D.: Kang. Y. J.: Park. K. H.: Lee. S. G.: Yoon. Y. J. J. Heterockt Chen. 2005 42. 353.

16. Kim. I. J.: Kweon. D. H.: Cho. S.-D.: Kim, H. K.: Jung. E. Y.: Lee, S. G.: Falck, J. R. Yoon, Y. J. Tetrahedron 2005, 61. 5889

17. Kunz, K.: Scholz. U.: Ganzer, D. Syzlett. 2003 , 2428.

18. Sun. P.: Weinreb. S. M.: Shang. M. J. Org Chent. 1997.62.8604.
19. Silveira. C. C.: Bernard. C. R.: Braga. A. L:: Kaufmant. T. S Sinlett. 2002. 907.

20. Kweon. D. H.: Kim. H. K.: Kim. T. T.: Chung. H. A.: Lee. W. S. Kim. S. K.: Yoon, Y. J. J. Heterocycl. Chem. 2002, 39. 203.

21. Kim. J. J.: Park. Y. D.: Lee. W. S.; Cho, S.-D.; Yoon, Y. J. Synthesis 2003. 10, 1517 .

22. Park. J. K.: Kiml. B. G.: Koo. I. S. Bull. Korean Chen. Soc. 2005. 26. 1795

23. Park. T. K.: Kim. B. G. Bull Korem Chem. Soc. 2006. 27. 1405

24. Whangbo. M.H; Stewart. K. R. J. Org. Chem. 1982. 47.736

25. Wang, L.: Hung. Y.-C.: Hwu, S.J.: Koo, H.-J.: Whangbo, M.-H. Chem Haterials 2006, 18, 1219 .

26. Frish. M. T.: Trucks. G. W.: Head-Gordon. M. H.: Gill. P. M. W.: Wong. M. W.: Foresman. J. B.: Johnson. B. G: Schlegel. H. B.: Robb. M. A.: Replogle. E. S.: Gomperts. R.: Andres. J. L: Raghavachari, K; Binkley. J. S.; Gonzalez. C.: Martin, R. L.: Fox. D. J: Defrees. D. J.; Baker. J.: Stewart, J. J. P: Pople. J. A. Gaussian 03: Gaussian Inc.: Pittsburgh. 2003.

27. McDaniel. D. H.: Browt1. H. C . J. Org Chem. 1958. 23. 420. 